\title{
Beyond the specific child What is 'a child's case' in general practice?
}

\author{
Bibi Hølge-Hazelton and Charlotte Tulinius
}

\begin{abstract}
Background

Too many abused and neglected children are being overlooked by GPs and other professionals who are in contact with the families. Some suggestions for a definition of 'a child in need' have been given, but the functionality of these definitions has not been tested in general practice.
\end{abstract}

Aim

To describe the problems presented by GPs as cases with children in need during supervision, and from here to suggest an empirically-based definition of a child in need in general practice.

Design of study

A mixed-method evaluation design was used.

Setting

Twenty-one GPs, in Denmark, participated in supervision groups concerning cases with children in need in general practice.

\section{Method}

The data were analysed via field notes and video recordings; case categorisation into sex, ethnicity, and developmental stages; thematically using the GPs' own descriptions; and a theoretically supported style.

\section{Results}

Analysis of the data led to the suggested definition of a case concerning 'a child in need' in general practice as one that directly or indirectly involves problems with a specific child, an as-yet unborn child, or one or both parents of a family currently or potentially threatening the wellbeing of the family or the child.

\section{Conclusion}

Based on this analysis, one suggestion as to why some abused and neglected children are overlooked in general practice is that GPs often have to navigate in difficult indirect consultations, where there is a high risk of losing the overview.

\section{Keywords}

children; education, medical, postgraduate; physician-patient relationship; primary health care; professional education.

\section{INTRODUCTION}

It is often wondered why child abuse is not discovered earlier by doctors or other professionals who are in contact with the families in which the abuse is occurring.

Do the professionals fail to spot these children and their families because other children's cases are more obvious or severe, which perhaps distracts the professionals' attention away from some abused children? Or do the signs of abuse and neglect lie outside most GPs' professional understanding of 'a child in need' case? Are the existing definitions not operational in a clinical context like general practice? The definition of 'a child in need' varies across disciplines, countries, and even regions. In line with other earlier offered definitions, ${ }^{1}$ the UK government defines children in need as:

'... those whose vulnerability is such that they are unlikely to reach or maintain a satisfactory level of health or development, or their health and

B Hølge-Hazelton, $R N, M S c N, P h D$, director of research, Roskilde Hospital; associate professor, The Research Unit for General Practice, Department of Public Health, Faculty of Health Sciences, University of Copenhagen, Copenhagen, Denmark. C Tulinius, MD, PhD, MHPE, medical director of curriculum, Royal College of General Practitioners, London; senior member, St Edmund's College, University of Cambridge, Cambridge, UK; senior researcher, Research Unit and Department of General Practice, University of Copenhagen, University of Copenhagen, Copenhagen, Denmark.

Address for correspondence

Bibi Hølge-Hazelton, The Research Unit for General Practice, Department of Public Health, Faculty of Health Sciences, University of Copenhagen, Øster Farimagsgade 5, PO Box 2099, DK-1014 Copenhagen, Denmark.

E-mail: bibihoe@sund.ku.dk

Submitted: 31 March 2009; Editor's response: 10 July 2009; final acceptance: 10 November 2009.

(OBritish Journal of General Practice

This is the full-length article of an abridged version published in print. Cite this article as: Br J Gen Pract 2010; DOI: 10.3399/bjgp10X482059. 
development will be significantly impaired, without the provision of services.'

There is an extensive theory-based literature that focuses on children in need. ${ }^{3}$ It is known that GPs' attention is awakened when they experience a child or family behaving 'abnormally' in the surgery, ${ }^{4}$ but empirically-based descriptions of the kind of problems children and families present to professionals like GPs are scarce. ${ }^{4}$

To explore how children in need are identified by GPs, and why abused children are sometimes overlooked, it is important to understand the variety of all children's cases that professionals find problematic or puzzling in their everyday clinical practice.

In Denmark, GPs have regular contact with all children from the age of 5 weeks to 5 years, as part of a public preventive healthcare programme (GPV). ${ }^{5}$ It is widely recognised that some families need a level of care that goes beyond the GPV. These families often bring the problems to the attention of the GPs directly, or indirectly via other problematic issues. ${ }^{4}$ However, even though GPs may be the first professionals to spot signs of possible child maltreatment, $^{3}$ there is no empirically-based definition of 'a child in need'. It seems crucial that such a definition is provided in order to understand future GP training needs for the improvement of child health care in general practice.

\section{METHOD}

To support GPs' professional development in working with these children and their families, a practice-based project was set up in Denmark from 2005 to 2007. It was designed and led by clinically experienced GP project managers with the intention of educating other GPs within this area. The aim of the project was to prevent the neglect of children through early and competent action in general practice and to strengthen the professional identity of the participating GPs in children's cases.

Two experienced researchers were hired to study, document, and evaluate the project. This process is described in detail elsewhere (C Tulinius and B HølgeHazelton, unpublished data, 2009).

The main intervention was participation of GPs in supervision groups, which focused on cases involving children from the GPs' clinical practices. Group supervision was chosen because it is a well-known method of organising peer groups among GPs in Denmark. $^{6}$ The methodology, the frequency of meetings, and the selection of participants and supervisors was inspired by the existing organisation of continuing professional development (CPD) in Danish general practice.

\section{How this fits in}

GPs are often in the forefront of public debates regarding children in need overlooked by healthcare professionals. Based on this empirical study it is suggested that one explanation for this could be that 'children in need' sometimes must be discovered by GPs in indirect consultations without the child being present. On the basis of this study, a new definition of what a 'child in need' is in general practice has been defined.

Twenty-one GPs, all educated and practising in Denmark, were invited to participate in three supervision groups over a 2-year period. Each group consisted of seven GPs, a typical number for Danish supervision groups. The participants represented three different geographical areas: urban, provincial, and rural; both sexes; and a range of ages, practice organisations, and clinical experiences as GPs. The selection was done through local GP tutors using the local networks of GPs to choose colleagues from their geographical area. The groups met eight to 10 times per year for 2-3 hours with their supervisor. The meetings were organised with a focus on cases from the GPs' surgeries that involved children.

The supervision in the project was inspired by methods already known from CPD groups in Danish general practice. It can be described as a collaborative conversation, ${ }^{7}$ where the participants attempted to create clarity and understanding of a social interaction as it took place among professionals in a given context. This interpretation of supervision, according to Schilling, is comprehensible for the concrete supervision healthcare professionals draw upon, regardless of the theoretical background of the supervision. ${ }^{8}$ In the concrete project, the supervisors were pragmatically recruited and had different backgrounds and experience as supervisors; two of the supervisors were GPs and one was a child psychologist.

\section{Theoretical frame of reference of the project}

The theoretical frame of reference of the project was the work of psychologist Carr. ${ }^{9}$ This model was introduced to the participating GPs as a suggestion for a framework for analysing cases involving children and families in the GPs' surgeries.

Carr's focus is psychological problems that occur during the first 18 years of life, a life span divided into three developmental stages or domains: early childhood, middle childhood, and adolescence. However, the development of children is seen as primarily a social process, where the family is the central social context for this development. ${ }^{9}$

Problems related to infancy and early childhood (0-6 years) are described as sleep problems, 
toileting problems, learning and communication difficulties, autism, and pervasive developmental disorders. Problems related to middle childhood (6-12 years) are described as behavioural problems, attention and overactivity problems, fear and anxiety problems, repetition problems, and somatic problems. Problems related to adolescence are described as drug abuse, mood problems, anorexia, bulimia nervosa, and schizophrenia.

Child abuse (physical abuse, emotional abuse, neglect, and sexual abuse) and adjustment to major life transitions are described individually and can be seen in all developmental stages. Carr has developed a model for systematising the factors that can be related to the problems. This model consists of four factors called 'the four Ps': predisposing factors; perpetuating factors; protective factors and provocative factors. The development of psychological problems may be conceptualised as arising from risk factors that predispose children to developing psychological problems, precipitating factors that trigger the onset or marked exacerbation of psychological difficulties, maintaining factors that perpetuate psychological problems once they have developed, and protective factors that prevent further deterioration and have implications for prognosis and response to treatment. $^{9}$

\section{Table 1. Data produced in the project.}

\begin{tabular}{ll} 
Method & Description \\
\hline Participant observation & $\begin{array}{l}\text { All sessions except one were observed and video } \\
\text { recorded in two of the three groups (province and } \\
\text { rural), and all sessions except three were observed in } \\
\text { the urban group. The data are equivalent to } 80 \text { hours } \\
\text { of video recording and field notes. }\end{array}$ \\
\hline Individual interviews & $\begin{array}{l}\text { Two GPs from each group were interviewed three } \\
\text { times; before the intervention began, midterm, and } \\
\text { after it ended. The data are equivalent to } 600 \text { pages } \\
\text { of interview transcriptions. }\end{array}$ \\
\hline Focus group interviews & $\begin{array}{l}\text { Three focus group interviews, one in each of the } \\
\text { groups by the end of the project. Equivalent to } \\
\text { approximately } 100 \text { pages of interview transcription. }\end{array}$ \\
\hline Email-based structured & $\begin{array}{l}\text { Evaluation questions related to the project aim and } \\
\text { the individual expectations; conducted midterm and } \\
\text { after the project ended. }\end{array}$ \\
\hline ePortfolio & $\begin{array}{l}\text { Developed for this project but with structure and user } \\
\text { facilities identical to the Danish GP specialty training } \\
\text { ePortfolio. Included } 185 \text { registered cases with } \\
\text { children, with } 550 \text { log entries of varied length, } \\
\text { in paper format }\end{array}$ \\
\hline \begin{tabular}{l} 
equivalent to 165 pages. \\
\hline Evaluation form including five questions regarding
\end{tabular} \\
$\begin{array}{l}\text { learning processes were filled out by the participating } \\
\text { GPs after each supervision session or workshop/ } \\
\text { lecture. In total, } 245 \text { schedules were received. }\end{array}$ \\
\hline
\end{tabular}

\section{Research design}

To assure methodological pluralism and to attain accountability for the educational quality, ${ }^{10}$ a mixedmethod evaluation design, ${ }^{11,12}$ was chosen. This included observation and video recordings of the sessions; ${ }^{13,14}$ individual qualitative interviews with six participants before the intervention began, midterm, and after it ended; ${ }^{15}$ focus group interviews with each group; ${ }^{16}$ and written evaluation questionnaires, continuous ePortfolios, and process evaluation forms, giving a wide range of data (Table 1). The analysis was inspired by Giorgi's phenomenological method of analysis. ${ }^{17}$ All data were used, but this article mainly focuses on analysis of the data obtained during participant observation and the video recordings of the supervision sessions from May 2005 to May 2007. Denzin identified four basic types of triangulation: ${ }^{18}$

1. data triangulation that involves time, space, and persons;

2. investigator triangulation that involves more than one researcher;

3. theory triangulation that involves using more than one theoretical scheme in the interpretation of the data; and

4. methodological triangulation that involves using more than one method to gather data.

In this case the analysis consisted of four steps representing all four basic types of triangulation using the combined expertise of the two researchers. Hence, the final interpretations are outcomes of an interactive and collaborative process.

1. The researchers went through all video recordings of the presented cases taking notes while observing them. ${ }^{13,14}$ Then these notes were compared to the field notes taken during supervision settings. Finally, these two sets of notes were combined into new research notes.

2. All cases were sorted by sex, ethnicity, and the developmental stages or 'domains', which, according to Carr, are the periods in children's lives where different problems usually emerge. ${ }^{9}$

3. The individual cases were categorised according to Carr's description of problems in each domain. However, even though many cases took their point of departure in this framework, almost half of the cases took their point of departure in a problem related to the parent(s).

4. As it became clear that the GPs themselves did not refer to the theoretical framework, and several of the cases had to be placed in a fourth category, it was decided to use the GPs' own description and categorisations as a new framework to 
Table 2. The presented cases in each of the supervision groups, described by age, sex, and ethnicity, and the four analysis categories.

\begin{tabular}{lccc} 
Categories & Urban $(18$ cases $)$ & Suburban $(24$ cases $)$ & Rural (28 cases) \\
\hline Early childhood & 4 boys 1 girls & 3 boys 1 girl & 1 boys 2 girls \\
\hline Middle childhood & 3 boys 1 girls & 2 boys 4 girls & 1 boys 3 girls \\
\hline Adolescence & 0 boys 3 girls & 1 boy 5 girls & 5 boys 3 girls \\
\hline Unborn/parents/other & 6 & 8 & 13 \\
\hline Other ethnic background than Danish & 3 & 6 & 5 \\
\hline
\end{tabular}

thematically analyse the cases..$^{19}$ The cases in the fourth category were described as:

- insecurity related to the parental role, such as finding a balance between work and family life;

- mutual expectations of the new roles as parents;

- difficulties in interpreting signs from the child;

- parental problems related to divorce, such as lonely, poor, or battered single mothers, or unconstructive communication between mother and father;

- parent(s) with a psychiatric problem, such as those with current or past psychiatric diagnoses;

- parents' abuse problems, such as those with current or past psychiatric diagnosis;

- parents' abuse problems, such as alcohol, medicine or food abuse;

- doctors' concern/potential case: such as fragile parents with previous history of neglect, loss of own parents, torture, prostitution or abuse, social isolation, unemployment; or

- heavily overweight parents.

\section{RESULTS}

In total, 70 cases were brought forward by the GPs in the three supervision groups. The cases were categorised demographically according to age, domains, sex, and ethnicity (Table 2). However, several of the cases primarily focused on parents in various problematic life circumstances with possible consequences for the family or even for an unborn child. A fourth category was therefore added to include these cases. These kinds of social and psychiatric problems in the family were presented in all supervision groups, but dominantly in the group of GPs from the rural area, where the unemployment rate was high and incomes were low.

Even though quite different cases were brought up in all of the three groups, the age and sex profile among the children across the three groups of GPs presented the same pattern. Cases concerning children or families with ethnic backgrounds other than white Danish were between $16 \%$ and $25 \%$ of the total number. The total percentage of immigrants in the Danish population is $6.3 \%$, and among these
$4.1 \%$ of the total population were from non-western countries. ${ }^{12}$

By using the words and concepts of the GPs in the analysis, the descriptions of the most urgent problem in the different age and sex groups showed that the GPs seldom described specific problems of specific children. They primarily described problems concerning the parental roles, such as behavioural problems and problems related to events like death, divorce, war, and torture:

- Case 1: since her divorce, the mother of two teenagers has started drinking a little. The father does not want contact with his children. The GP can see that the whole family feels terrible and the GP is frustrated because there is nothing relevant to refer them to.

- Case 2: a mother with preschool child; the problem is access to the father, whom the mother describes as a psychopath. The mother wants to go into hiding with the child and consults the GP.

- Case 3: a toddler spoils things in the GP's office and the parents are completely passive. The GP is irritated by the child but does not want to expose the parents.

The main concerns raised by GPs in the supervision groups were problems related to parental dysfunction, neglect, suspicion of physical abuse, somatisation of healthy children, overprotecting a chronically ill child, mentally ill parents, and alcohol and drug abuse and violence among parents:

- Case 4: a concerned neighbour of an alcoholic divorced mother of two children calls the GP. The GP knows the mother but not the children.

- Case 5: both parents of an infant child are former drug users. The boy is thriving but the doctor is concerned about his future.

- Case 6: both parents of an infant child are mentally ill. The GP is concerned about their parental roles.

Thus, many of the cases can be described as a form of 'indirect consultation' for children, occurring when the GPs become aware of a patient's 
problematic family circumstances. Several cases even described potential problems for an unborn child:

- Case 7: a young pregnant women with a violent boyfriend; the doctor is concerned about the woman's capability for motherhood.

During the analysis of the words and concepts of the GPs, three things became clear:

1. It was characteristic for all supervision groups that almost half of all the presented cases were brought up in the supervision because of the doctor's anticipation of a potential problem or worry for the child/family, and not because the parents themselves presented the topic to the GP as a problem.

2. Very few cases concerned children whom the GP had actually been in recent direct contact with, or seen. Instead the child came into focus via the encounter with the parents.

3. The core of the child cases discussed was very much the same across the three groups, with the exception of cases within the added fourth category. Those kinds of child cases were more frequently presented in the group from the rural area.

These three conclusions made it possible to divide the cases into two categories:

- cases concerning a specific problem for a specific child; and

- cases concerning problematic family issues with or without the presence or involvement of a specific child.

Each of these categories was a case emerging because of either parents' or doctors' concern.

The four steps of analysis of the presented cases led to a suggestion for the definition of what a case with 'a child in need' is in general practice:

'A "child in need" in general practice is a case that directly or indirectly involves problems with a specific child, an as-yet unborn child, or one or both parents of a family, currently or potentially threatening the wellbeing of the family or the child.'

This means that many of the cases concerning children in need in general practice are found in indirect consultations of the child concerned indirect in the sense that the child is not present, or the case is identified via other factors not directly involving the child.

\section{DISCUSSION}

\section{Summary of main findings}

The GPs were not observed working with the project's theoretical frame of reference, and they appeared to not find it helpful under the given conditions.

Many of the cases brought up in the supervision sessions were complex, in the sense that they involved more than one problem in the family, and it was necessary to add a category to include parental problems, and problems in contemporary families, as well as problems with psychiatry, violence, and abuse in the family. One of the challenges seems to be that the cases took their point of departure in the parent, whereas the focus of the theory is the child.

This is supported by previous findings that vulnerability occurs in childhood when several problematic factors are present at the same time, and that it is this accumulation that should be addressed because it puts a strain on the child..$^{22,23}$

By analysing the words and concepts used by the GPs, it became clear that across all cases and categories, the main concerns presented by the parents did not involve children directly, but rather issues of dealing with parenthood and life events.

Based on the analysis, it is suggested that 'cases involving children in need' should be defined for general practice. This definition will differ from other definitions, in that such cases are often 'indirect': the child in need may not be present at the GP's consultation; indeed, the primary cause for the consultation itself may not even be the child.

\section{Strengths and limitations of the study}

The project design gave the possibility of authenticity in the professional development and the results are based on different kinds of triangulated data. . $18,23,24^{2}$

The structure of the project enabled discussions regarding the cases the GPs had spotted, but by definition they could not discuss the ones they missed. Moreover, cases were presented as retrospective reconstructions seen from the GPs' subjective points of view.

The cases can be perceived as not reflecting the most common situations, but rather the difficult exceptions as opposed to the cases that were less challenging to the GPs' professionalism.

The participants could all be described as white and as doctors representing the middle class. This is likely to have influenced the choice of cases presented, ${ }^{25,26}$ and could probably also have influenced the kind of information and concerns the patients chose to share with their GPs.

\section{Comparison with existing literature}

In earlier studies, there has been a lack of empiricallybased descriptions of the kinds of problems children 
and families present to professionals like GPs. ${ }^{4}$ This study has generated an empirically-based definition reflecting the everyday in general practice, leading to the suggested definition of what constitutes a case with 'a child in need' in general practice.

The GPs' focus in the description of the 'case' were circumstances for a possible future problem, rather than the explanation of an existing child problem. This underlines the general practice preventive perspective as opposed to the focus on the aetiological or pathological explanation of an existing child problem.

The number of cases involving children and/or parents with other ethnic backgrounds than white Danish was relatively high. Bearing in mind the existing knowledge about social capital as an important determinant of children's health, ${ }^{27}$ this result could be due to the general condition that ethnic minority populations are marginalised compared to the rest of the population. ${ }^{20}$

The GPs did not use the introduced theoretical framework. In other Nordic studies, a lack of theoretical knowledge has been described as an obstacle to GPs' opportunity for acting professionally., ${ }^{429}$ An alternative interpretation could be the lack of relevance and lack of transferability of knowledge produced in other medical specialties or disciplines to the complex reality of clinical general practice.

\section{Implications for future research}

It is extremely important to draw attention to the finding that many of the children's cases in fact did not originate from children's problems but from problems among adults with children. If Carr's theoretical framework is to be used in general practice it needs further development.

\section{Funding body}

This work was supported by The Danish Ministry of Health and 'PLU-fonden' (GPs' research Foundation in Denmark)

\section{Ethics committee}

The data have only been available to the authors and are only used for documentation and research presentations related to this project. The study was approved by the Danish Data Protection Agency. No personal data were revealed in the cases presented by the GPs in the supervision settings or in any of the other data, as they were instructed to work with the cases of the children in an anonymous format

\section{Competing interests}

The authors have stated that there are none

\section{Acknowledgements}

The authors would like to thank the participating GPs who, by allowing us to use their reflections, made it possible for us to write this paper.

\section{Discuss this article}

Contribute and read comments about this article on the Discussion Forum: http://www.rcgp.org.uk/bjgp-discuss

\section{REFERENCES}

1. Province of Manitoba. The revised Manitoba guidelines on identifying and reporting a child in need of protection (including child abuse). Winnipeg, MB: The Provincial Advisory Committee on Child Abuse, 2001.
2. Department for Children, Schools and Families. Every child matters http://www.dcsf.gov.uk/everychildmatters/safeguardingandsocialcare/saf eguardingchildren/safeguarding/ (accessed 3 Dec 2009).

3. Newton AW, Vandeven AM. Update on child maltreatment. Curr Opin Pediatr 2009; 21(2): 252-261.

4. Lykke $\mathrm{K}$, Christensen P, Reventlow S. 'This is not normal ... - signs that make the GP question the child's well-being. Fam Pract 2008; 25(3): 146-153.

5. Danish National Board of Health. Preventive health care examinations for children and vaccinations. Albertslund: Sundhedsstyrelsens Publikationer, 2007. http://www.sst.dk/publ/Publ2008/CFF/Vacc/Bus_vacc_sep07-eng.pdf (accessed 20 Nov 2009).

6. Stroebech J. Supervision. In: Kaltoft S, Thorgaard L (eds). Maanedsskrift prakt laegegerning. [The doctor as the drug.] Copenhagen: Laegeforeningens Forlag, 2005: 135-144.

7. Anderson H, Swim S. Supervision as collaborative conversation: connecting the voices of supervisor and supervisee. J Syst Ther 1995; 2: $1-13$.

8. Schilling B. Systematic supervision methodology. [in Danish] Virum: Psykologisk Forlag, 1997.

9. Carr A. The handbook of child and adolescent clinical psychology. A contextual approach. London: Brunner-Routledge; 2003.

10. Burke Johnson R, Onwuegbuzie AJ. Mixed methods research: a research paradigm whose time has come. Educ Res 2004; 33(7): 14-26.

11. Creswell J, Clark Plano VL. Designing and conducting mixed methods research. Thousand Oaks, CA: Sage Publications, 2007.

12. Protheroe J, Bower P, Chew-Graham C. The use of mixed methodology in evaluating complex interventions: identifying patient factors that moderate the effects of a decision aid. Fam Pract 2007; 24(6): 594-600.

13. Adler AA, Adler P. Observational techniques. In: Denzin NK, Lincoln YS (eds). Collecting and interpreting qualitative materials. London: Sage Publications, 1998: 79-109.

14. Lofland J, Lofland LH. Analysing social settings. A guide to qualitative observation and analysis. London: Routledge, 1984.

15. Spradley JP. The ethnographic interview. New York, NY: Holt, Rinehart and Winston; 1979.

16. Greenbaum TL. The handbook of focus group research. 2nd edn. London: Sage Publications, 1998.

17. Giorgi A. Sketch of a psychological phenomenological method. In: Giorgi A (ed). Phenomenology and psychological research. Pittsburgh, PA: Duquesne University Press, 1985; 1-22.

18. Denzin N. Sociological methods: a sourcebook. 5th edn. New Brunswick, NJ: Trancaction Publishers, 2006.

19. Aronson J. A pragmatic view of thematic analysis. Qual Rep 1994; 2(1): http://www.nova.edu/ssss/QR/BackIssues/QR2-1/aronson.html (accessed 25 Nov 2009).

20. Dahl KM. Etniske minoriteter i tal. [Ethnic minorities in numbers.] Copenhagen: The Danish National Centre for Social Research, 2005.

21. Reinhardt Pedersen C, Madsen M. Parents' labour market participation as a predictor of children's health and wellbeing: a comparative study in five Nordic countries. J Epidemiol Community Health 2002; 56(11): 861-867.

22. Ploug N. Socialt udsatte børn. Identifikation, viden og handlemuligheder $i$ daginstitutioner. [Socially neglected children. Identification, knowledge and possibilities of action in daycare institutions.] Copenhagen: The Danish National Centre for Social Research, 2002.

23. Malterud K. Qualitative research: standards, challenges, and guidelines. Lancet 2001; 358(9280): 483-488.

24. Denzin, NK. Sociological methods: a sourcebook. 2nd edn. New York, NY: McGraw Hill, 1978.

25. Street RL Jr, O’Malley KJ, Cooper LA, Haidet P. Understanding concordance in patient-physician relationships: personal and ethnic dimensions of shared identity. Ann Fam Med 2008; 6(3): 198-205.

26. Street RL Jr, Gordon H, Haidet P. Physicians' communication and perceptions of patients: is it how they look, how they talk, or is it just the doctor? Soc Sci Med 2007; 65(3): 586-598.

27. Berntsson L, Köhler L, Vuille JC. Health, economy and social capital in Nordic children and their families: a comparison between 1984 and 1996. Child Care Health Dev 2006; 32(4): 441-451.

28. Geertz C. The interpretation of cultures: selected essays. New York, NY: Basic Books, 1973.

29. Hølge-Hazelton B, Christensen I. In a unique position or squeezed out? The professional roles of general practitioners in cancer care in general and of young adult cancer patients in particular. J Cancer Educ 2009; 24(4): 326-330. 